\title{
RANCANG BANGUN ALAT PENDETEKSI KADAR GULA PADA MINUMAN BERPERISA MENGGUNAKAN SENSOR KAPASITIF
}

\author{
Vina Tri Hartini ${ }^{l}$ \\ ${ }^{1}$ Jurusan Teknik Elektronika, Politeknik Elektronika Negeri Surabaya
}

Email Coprespondent Author : vintrih@gmail.com

\begin{abstract}
In the composition, many packaged drinks are contain a fairly high sugar level, so that if consumed in excess without regard to the limit of sugar intake per serving, it can cause various diseases, especially diabetes mellitus. According to nutrition and health expert, Brigitte Zeitlin, recommends for choosing foods/drinks that serve no more than $\mathbf{1 0}$ grams of sugar per serving. In this research, a device that can control sugar intake per serving is made. Measurements are carried out by taking the voltage value from the drink, then converting it using the regression analysis method so that it can display the amount of sugar level in the solution and a description of the status of sugar.
\end{abstract}

Keyword - Sugar level, flavored drink, parallel plat capacitor, capacitive sensor, refractometer.

Abstrak - Dalam komposisinya, minuman kemasan yang banyak dijual memiliki kandungan kadar gula yang cukup tinggi sehingga apabila dikonsumsi secara berlebihan tanpa memperhatikan batas asupan kadar gula per porsinya dapat menimbulkan berbagai macam penyakit terutama penyakit diabetes mellitus. Menurut pakar nutrisi dan kesehatan, Brigitte Zeitlin, menyarankan untuk memilih makanan/minuman yang menyajikan tidak lebih dari 10 gram gula per porsinya. Dalam penelitian ini dibuat sebuah alat yang dapat mengontrol asupan kadar gula per porsinya. Pengukuran dilakukan dengan cara mengambil nilai tegangan dari minuman, lalu dikonversi menggunakan metode analisis regresi sehingga dapat menampilkan jumlah kadar gula pada larutan dan keterangan status kadar gula.

Kata kunci - Kadar gula, minuman berperisa, kapasitor keping sejajar, sensor kapasitif, refractometer.

\section{PENDAHULUAN}

Sukrosa banyak sekali digunakan dalam sektor industri pangan salah satunya pada industri minuman. Minuman berperisa merupakan salah satu minuman yang popular di berbagai kalangan masyarakat, baik muda dan tua masingmasing menyukai minuman yang memiliki rasa manis dan menyegarkan tersebut. Karena kepraktisannya banyak orang memilih untuk mengonsumsi minuman tersebut yang mudah didapatkan di toko kelontong maupun swalayan besar. Minuman tersebut jika dikonsumsi dalam jangka panjang akan menimbulkan penyakit Diabetes Mellitus (DM) yang lebih dikenal dengan sebutan kencing manis, yang sebagian besar disebabkan oleh pengonsumsian gula yang berlebihan.

Pentingnya sebuah alat pengukur kadar asupan gula dalam minuman atau bahan pangan lainnya dapat membantu mengetahui jumlah kadar gula yang masuk ke dalam tubuh, sehingga tidak melebihi batas konsumsi gula harian. Hingga saat ini alat untuk mengukur kadar gula sangat jarang ditemukan, pengukuran kadar gula yang umum adalah untuk mengukur kadar gula dalam darah. Walaupun begitu, terdapat beberapa metode yang bisa digunakan untuk mengukur kadar gula pada makanan dan minuman salah satunya adalah memanfaatkan prinsip kerja refraktometer (refraksi cahaya). Namun, alat yang menggunakan prinsip kerja refraksi cahaya masih memiliki kelemahan, yaitu sensitif terhadap sinar matahari sehingga saat pengujian di lapangan yang terkena paparan sinar matahari akan mendapatkan nilai yang kurang akurat akibat adanya bias cahaya.

Berdasarkan hal tersebut, penulis tertarik untuk melakukan penelitian tentang rancang bangun alat pendeteksi kadar gula pada minuman berperisa menggunakan sensor kapasitif sebagai bentuk implementasi pengetahuan yang didapatkan selama ini.

\section{RINGKASAN FORMAT MANUSKRIP}

Menurut Raini dan Isnawati (2011), asupan gula per orang hanya 17 pound atau sebanyak 8.500 gram pertahunnya, kenaikan terjadi secara signifikan pada tahun 1980 menjadi 124 pound atau sekitar 62.000 gram dan pada akhir-akhir ini konsumsi gula menjadi 155 pound pertahunnya. Menurut Sasmiyanto (2019), peningkatan konsumsi gula tersebut relevan dengan estimasi jumlah penderita diabetes mellitus di Indonesia pada tahun 2000, yaitu sekitar 8,4 juta penduduk dan akan diperkirakan akan meningkat pada tahun 2030 menjadi 21,3 juta jiwa. Kondisi tersebut menempatkan Indonesia menjadi negara keenam dengan jumlah penderita diabetes mellitus terbanyak di dunia. Oleh karena itu, disarankan bagi semua orang untuk tidak mengkonsumsi makanan dan minuman manis secara berlebihan untuk mencegahnya terserangnya penyakit.

Secara fisik, gula bisa berupa padatan dan larutan, yang mana larutan terbagi menjadi dua yaitu larutan elektrolit dan non-elektrolit. Dalam bukunya, Raymond Chang (2003) menyatakan bahwa dalam bentuk larutan, gula merupakan molekul yang tidak bermuatan listrik. Berdasarkan teori tersebut dapat diterapkan pada penelitian yang akan dilakukan dengan menggunakan kapasitor keping sejajar. Kapasitor keping sejajar merupakan suatu komponen 
elektronika yang berfungsi untuk menyimpan muatan listrik, yang terdiri dari dua keping plat konduktor yang diletakkan secara sejajar dan dipisahkan oleh suatu bahan dielektrik. Sifat dari Bahan dielektrik yang digunakan merupakan bahan isolator yang dapat menampung muatan elektron untuk level tegangan tertentu.

\section{A. Kapasitor Keping Sejajar}

Kapasitor keeping sejajar terbuat dari dua buah keping konduktor yang diletakkan sejajar atau berhadapan dengan jarak tertentu yang dipisahkan oleh bahan dielektrik. Kapasitor keping sejajar akan bekerja jika telah dihubungkan dengan suatu alat yang bermuatan (misalnya baterai dan power supply) dan akan menghantarkan muatan dari masing-masing konduktor hingga beda potensial pada kutub positif dan kutub negatif bernilai sama dengan beda potensial kutub positif dan kutub negatif pada baterai atau power supply tersebut.

Kapasitor keping sejajar memiliki nilai kapasitansi sebesar :

$$
C=\frac{\varepsilon_{O} A}{d}
$$

Dimana :

$\mathrm{C}=$ Kapasitansi (Farad)

$\varepsilon_{O}=$ Permitivitas ruang hampa $=8,85 \times 10^{-12} \mathrm{C}^{2} / \mathrm{Nm}^{2}$

$\mathrm{A}=$ Luas penampang masing-masing keping $\left(\mathrm{m}^{2}\right)$

$\mathrm{D}=$ Jarak antar keping

\section{B. Kapasitor Dalam Medan Listrik}

Kapasitor merupakan piranti elektronika yang dapat mengisi dan membuang muatan. Setelah kapasitor terisi penuh maka kapasitor akan menutup aliran arus listrik dalam proses ini kapasitor sedang menyimpan muatan. Kapasitor dapat memblokir arus searah karena kapasitor tidak dapat dilalui oleh arus listrik searah. Dalam rangkaian $\mathrm{AC}$, arus akan tetap mengalir karena muatan listrik yang terkumpul diantara konduktor pada kapasitor tidak akan pernah mencapai keseimbangan

Menurut Nuwair (2009), hambatan total dari rangkaian kapasitor dengan resistor dan induktor pada rangkaian AC dikenal dengan impedansi. Rangkaian pada Gambar 1 merupakan rangkaian yang digunakan oleh Soltani, et al (2010) dalam penelitiannya untuk memprediksi kualitas pisang selama tahap pematangan.

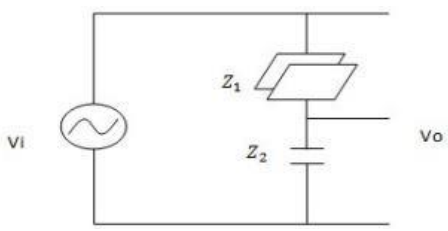

Gambar 1. Rangkaian Sensor Kapasitor Keping Sejajar

\section{Analisis Regresi}

Analisis regresi merupakan salah satu metode analisis data untuk mengamati kecenderungan perubahan pada suatu fenomena. Analisis regresi dibagi menjadi dua jenis yaitu analisis regresi linier dan analisis regresi algoritmik. Analisis regresi linier banyak digunakan untuk mengamati pengaruh suatu variabel terhadap variabel lainnya. Regresi linier sederhana didasarkan pada hubungan fungsional ataupun kausal antara satu variabel indepeden dengan satu variable dependen. Persamaan umum regresi linier sederhana adalah sebagai berikut :

$$
\dot{\mathrm{Y}}=\mathrm{a}+\mathrm{bX}
$$

Dimana :

$\dot{\mathrm{Y}}=$ subyek dalam variable dependen yang diprediksikan.

$\mathrm{a}=$ nilai $\mathrm{Y}$ bila $\mathrm{X}=0$ (nilai konstan).

$\mathrm{b}=$ koefisien regresi.

$\mathrm{X}=$ subyek pada variable independen yang mempunyai nilai tertentu.

\section{METODE PENELITIAN}

Pada penelitian ini digunakan metode eksperimen. Metode eksperimen adalah melakukan penelitian dengan membuat sistem alat pendeteksi kadar gula pada minuman berperisa dengan menggunakan sensor kapasitif yang terbuat dari kapasitor keping sejajar.

\section{A. Perancangan Sistem}

Adapun gambar perancangan sistem pada alat ditunjukkan pada gambar 2 .

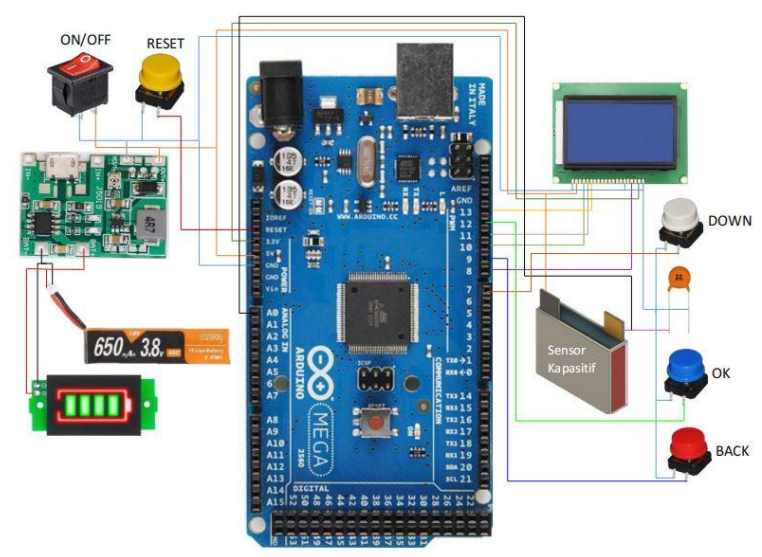

Gambar 2. Perancangan Sistem

\section{B. Blok Diagram Perancangan Alat}

Penggunaan blok diagram bertujuan untuk memudahkan dalam memahami suatu sistem dan kegunaannya pada sebuah alat. Berikut merupakan blok diagram alat pada gambar 3 . 


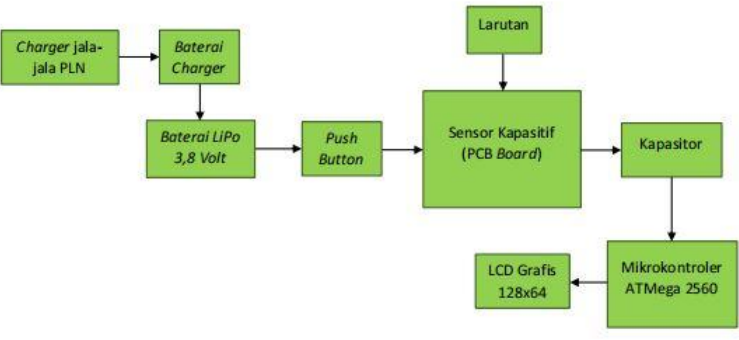

Gambar 3. Blok Diagram Sistem

\section{Flowchart Sistem}

Flowchart penelitian dari sistem alat yang dibuat ditunjukkan pada gambar 4 .

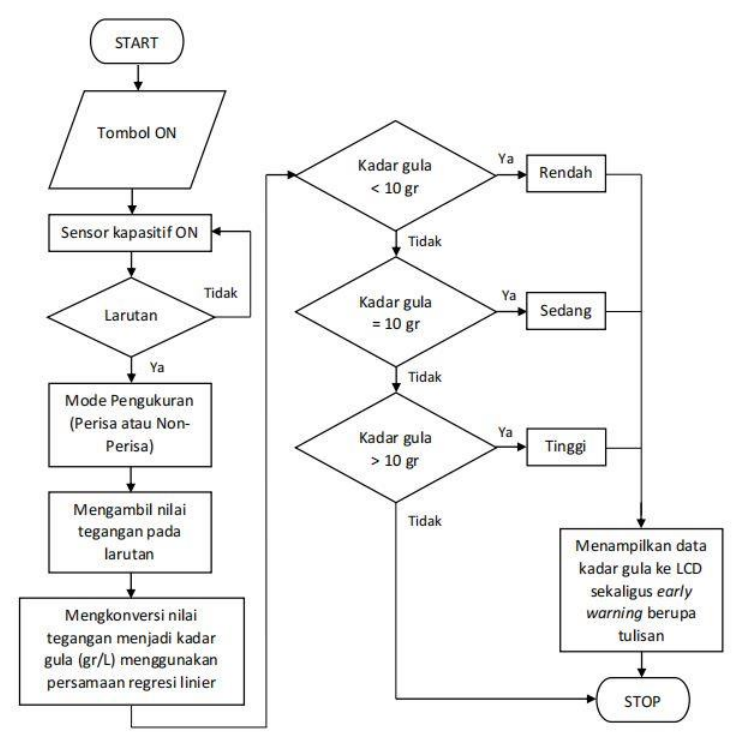

Gambar 4. Flowchart Sistem

\section{HASIL RANCANGAN SISTEM}

\section{A. Spesifikasi Alat}

Adapun model alat yang telah dibuat yaitu alat pendeteksi kadar gula pada minuman berperisa adalah sebagai berikut :

1. Box Sistem :

- Panjang

$=14 \mathrm{~cm}$

- Lebar

- Tinggi

- Berat

$=11 \mathrm{~cm}$

$=5 \mathrm{~cm}$

$=347 \mathrm{gram}$

2. Box Sensor:

- Panjang

- Lebar

- Tinggi

- Berat
$=14 \mathrm{~cm}$

$=5 \mathrm{~cm}$

$=3 \mathrm{~cm}$

$=150$ gram
3. Sensor :

- Panjang keping $\quad=4 \mathrm{~cm}$

- Lebar keping $=3 \mathrm{~cm}$

- Jarak antar keping $\quad=0,8 \mathrm{~cm}$

- Berat = 24 gram

4. Baterai :

- Panjang baterai $\quad=6,3 \mathrm{~cm}$

- Tinggi baterai $=1,6 \mathrm{~cm}$

- Kapasitas tegangan $\quad=3,8$ Volt

- Kapasitas daya baterai $\quad=650 \mathrm{mAh}$

- Berat = 12 gram

5. Berat Alat Total :

- $\quad$ Massa Alat $=\mathrm{M} 1+\mathrm{M} 2+\mathrm{M} 3+\mathrm{M} 4$

$$
=347 \mathrm{~g}+150 \mathrm{~g}+24 \mathrm{~g}+12 \mathrm{~g}
$$$$
=533 \mathrm{gram}
$$

\section{B. Prinsip Kerja Alat}

Terdapat 5 push button yaitu tombol on digunakan untuk menyalakan alat, tombol up dan down digunakan untuk memilih menu pengukuran (pengukuran larutan non perisa atau dengan perisa), tombol OK untuk mengeksekusi pilihan menu yang dipilih, dan tombol reset digunakan untuk mengembalikan hasil ukur kadar gula pada LCD ke posisi nol. Sensor kapasitif akan mendeteksi nilai tegangan dari larutan gula baik menggunakan perisa ataupun tanpa perisa kemudian nilai analog sensor masuk ke persamaan regresi linier yang sudah ditanam untuk selanjutnya dikonversi menjadi nilai kadar gula larutan dalam satuan gr/dL. Nilai kadar gula yang sudah terukur akan ditentukan level statusnya (rendah - sedang - tinggi) dan jika level status menunjukkan status Tinggi, maka sistem peringatan dini akan muncul berupa tulisan pada LCD untuk memepringatkan pengguna agar segera membatasi kadar gula pada porsi makan selanjutnya.

Persamaan regresi yang digunakan pada sistem untuk mengonversi nilai tegangan larutan gula (Volt) menjadi kadar gula $(\mathrm{Gr} / \mathrm{dL})$ ditunjukkan pada persamaan 3 dan 4 berikut.

$$
\mathrm{Y}=71.90 * \mathrm{X}-0.56
$$

Keterangan :

$\mathrm{Y} \quad=$ Kadar Gula Non-Perisa $(\mathrm{Gr} / \mathrm{dL})$

$\mathrm{X} \quad=$ Tegangan Larutan Gula Non-Perisa (Volt)

$$
\mathrm{Y}=72.23 * \mathrm{X}-2.77
$$

Keterangan :

$\mathrm{Y}=$ Kadar Gula Berperisa $(\mathrm{Gr} / \mathrm{dL})$

$\mathrm{X} \quad=$ Tegangan Larutan Berperisa (Volt)

Persamaan pengonversi diatas didapatkan dengan bantuan software Matlab agar lebih akurat. persamaan regresi 3 dan 4 merupakan persamaan regresi linear yang menyatakan bahwa semakin tinggi kadar gula yang terkandung dalam larutan maka semakin tinggi pula tegangan yang dihasilkan. 


\section{HASIL DAN PEMBAHASAN}

Pengujian alat dilakukan dengan menggunakan 4 sampel larutan uji dengan kadar gula yang berbeda. Larutan tersebut yaitu teh pucuk, kopikap, dan dua larutan gula murni tanpa campuran perisa dengan jumlah kadar gula yang berbeda. Hasil pengujian alat ditunjukkan pada gambar 5 berikut.

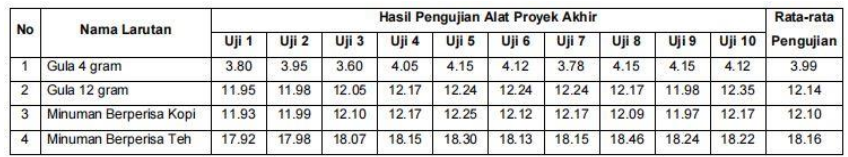

Gambar 5. Tabel Data Pengujian Kadar Gula dengan Alat

Dari pengujian yang dilakukan, diketahui besar error antara Alat yang telah dibuat dengan refractometer. Error yang didapat ditunjukkan pada tabel 1 berikut.

TABEL I

Perbandingan Data PENGUJian Kadar Gula PadA ALAT DENGAN REFRAKTOMETER

\begin{tabular}{|l|c|c|c|}
\hline \multicolumn{1}{|c|}{$\begin{array}{c}\text { Nama } \\
\text { Larutan }\end{array}$} & $\begin{array}{c}\text { Kadar } \\
\text { Gula pada } \\
\text { Alat (Brix) }\end{array}$ & $\begin{array}{c}\text { Kadar Gula } \\
\text { pada } \\
\text { Refraktometer } \\
\text { (Brix) }\end{array}$ & $\begin{array}{c}\text { Nilai Error } \\
\text { (\%) }\end{array}$ \\
\hline $\begin{array}{l}\text { Gula Murni } \\
4 \text { Gram }\end{array}$ & 3.99 & 3.91 & 2.05 \\
\hline $\begin{array}{l}\text { Gula Murni } \\
12 \text { Gram }\end{array}$ & 12.14 & 11.82 & 2.71 \\
\hline $\begin{array}{l}\text { Minuman } \\
\text { Berperisa } \\
\text { Teh }\end{array}$ & 12.10 & 11.70 & 3.42 \\
\hline $\begin{array}{l}\text { Minuman } \\
\text { Berperisa } \\
\text { Kopi }\end{array}$ & 18.16 & 17.81 & 1.97 \\
\hline \multicolumn{4}{|c|}{ Rata-Rata Error (\%) } \\
\hline
\end{tabular}

Dari tabel diatas, dapat diketahui grafik perbandingan data pengujian kadar gula antara alat dengan refractometer seperti pada gambar 6 berikut.

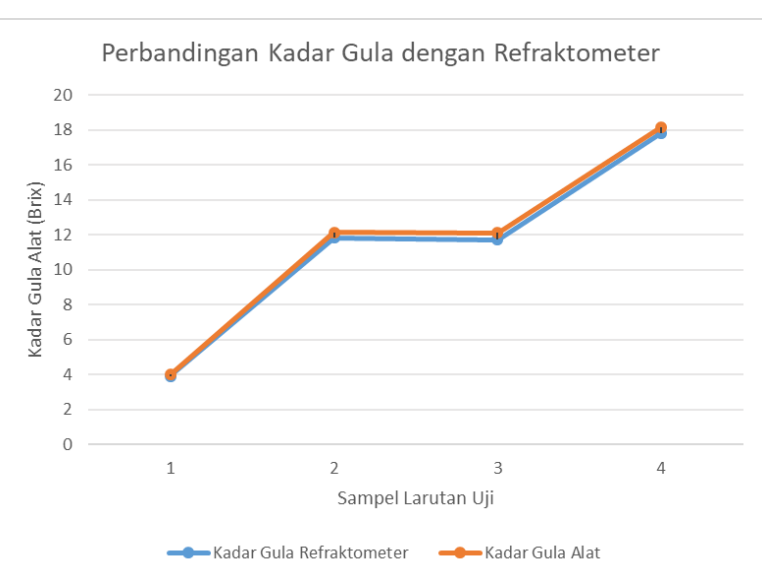

Gambar 6. Grafik Perbandingan Kadar Gula antara Alat dengan Refraktometer

\section{KESIMPULAN}

Dari pengujian yang telah dilakukan dengan memberikan 4 sampel larutan gula dengan jumlah gula yang berbeda pada alat yang telah dibuat dan refractometer sebagai alat referensi, diketahui bahwa terdapat error dari hasil pengukuran yaitu sebesar $2.54 \%$. Error tersebut dapat timbul karena beberapa faktor, yaitu adanya getaran halus atau guncangan saat mengukur kadar gula pada larutan dan bisa disebabkan karena takaran jumlah larutan $(\mathrm{dL})$ yang digunakan tidak sama.

\section{DAFTAR ACUAN}

[1] M. Raini dan A. Isnawati, "Kajian Khasiat Dan Keamanan Stevia Sebagai Pemanis Pengganti Gula," Media Litbang Kesehatan., vol. 21, no. 4, 2011.

[2] R. Chang, General Chemistry : The Essential Concepts, New York: McGraw-Hill, 2014.

[3] Nuwaiir, "Kajian Impedansi dan Kapasitansi Listrik pada Membran Telur Ayam Ras," Institut Pertanian Bogor, 2009.

[4] M. S. Firouz, M. Omid, and Alimardani, "Prediction of Banana Quality During Ripening Stage Using Capacitance Sensing System," Australian Journal of Crop Sciense., vol. 4, no. 6 , pp. 443-447, 2010 